\title{
Laparoscopic Management of Ectopic Pregnancy at Birat Medical College \& Teaching Hospital, Morang, Nepal
}

\author{
Neupane BB, ${ }^{1 *}$ Karki GMS, ${ }^{2}$ Dahal $P^{3}$ Karki $S B^{4}$
}

\section{Affiliation}

1. Lecturer, Department of obstetrics and Gynecology, Birat Medical College and Teaching Hospital, Tankisinuwari, Morang, Nepal.

2. Department of Obstetrics and Gynecology, Birat Medical College and Teaching Hospital, Tankisinuwari, Morang, Nepal.

3. Assistant Professor, Department of Obstetrics and Gynecology, Birat Medical College and Teaching Hospital, Tankisinuwari, Morang, Nepal.

4. Department of Anesthesiology, Birat Medical College and Teaching Hospital, Tankisinuwari, Morang, Nepal.

\section{ARTICLE INFO}

\section{Article History}

Received : 2 Feb, 2017

Accepted : 2 April, 2017

Published : 30 April, 2017

(c) Authors retain copyright and grant the journal right of first publication with the work simultaneously licensed under Creative Commons Attribution License CC - BY 4.0 that allows others to share the work with an acknowledgment of the work's authorship and initial publication in this journal.

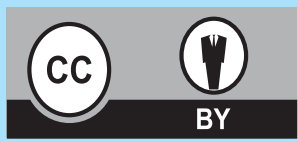

ORA 16

\section{* Corresponding Author}

Dr. Bhanubhakta Neupane Lecturer

Department of Obstetrics and Gynecology

Birat Medical College and Teaching Hospital

Tankisinuwari, Morang, Nepal.

Email: bhanubutwal@gmail.com

\section{Citation}

Neupane BB, Karki GMS, Dahal P, Karki SB. Laparoscopic Management of Ectopic Pregnancy at Birat Medical College \& Teaching Hospital, Morang, Nepal. BJHS 2017; 2 (1)2 : 106-109.

\section{ABSTRACT}

\section{Introduction}

Ectopic pregnancy is the most life threatening emergency in first trimester of pregnancy. Laparoscopic methods for treating ectopic pregnancy have made it preferred surgical technique over laparotomy. Most of the ectopic pregnancies can now be treated by laparoscopy.

\section{Objective}

To study outcome of laparoscopic management of ectopic pregnancy.

\section{Methodology}

A hospital based cross-sectional study was conducted at Birat Medical College and Teaching hospital from May 2013 to April 2016. The informed consent was taken from patients. The collected data was entered in Microsoft Excel and analyzed SPSS.

\section{Results}

All 89 cases of ectopic pregnancies were managed by laparoscopy. All were tubal pregnancies. Salpingectomy was done in 88 cases and salpingostomy in one case without any significant postoperative complications. There was no maternal mortality and no conversion to laparotomy.

\section{Conclusion}

Treatment of ectopic pregnancy by laparoscopy is effective with decreased postoperative morbidity.

\section{KEY WORDS}

Ectopic pregnancy, hemoperitoneum, laparoscopy, salpingectomy 


\section{INTRODUCTION}

The implantation of embryo outside the endometrial lining of endometrial cavity is called ectopic pregnancy. Ectopic pregnancy not only causes loss of pregnancy, but it is also associated with increased maternal morbidity and mortality. ${ }^{1}$ Most of the ectopic pregnancies may be life threatening if they are not managed in time. Clinical presentations of ectopic pregnancy vary from nonsymptomatic cases to massive intraperitoneal hemorrhage leading to hemodynamic instability. Classical triad of ectopic pregnancy including amenorrhoea, abdominal pain and per vaginal bleeding is not seen all cases. Attending gynecologist or physician should have high index of suspicion for diagnosis of ectopic pregnancy.

Laparotomy is the commonly performed surgical procedure for the treatment of ectopic pregnancy. ${ }^{1}$ But, laparoscopy approach is emerging as preferred surgical method for diagnosis and management of ectopic pregnancy as it allows direct visualization of ectopic gestation with simultaneous management with salpingectomy or salpinostomy. In Nepal, laparoscopic gynecological surgery has been just introduced in few hospitals only. Management of ectopic pregnancy by laparoscopic surgery is performed by limited numbers of gynecologists. As there is no published study on laparoscopic management of ectopic pregnancy in context of Nepal, this study is aimed to analyze the outcome of laparoscopic management of ectopic pregnancy in hospital in eastern part of Nepal so that safety and efficacy of laparoscopic surgery for the management of ectopic pregnancy could be ascertained.

Salpingectomy is the common surgical method for the treatment of ectopic pregnancy. But, fallopian tube can be preserved in selected cases. If the contralateral fallopian tube is normal, salpingectomy is the better option. ${ }^{2}$ Management of ectopic pregnancy by laparoscopic procedure is safe and effective with less analgesia requirement and shorter hospital stay when compared with laparotomy. ${ }^{3}$ significantly fewer adhesions develop in laparoscopic surgery. ${ }^{4}$

\section{METHODOLOGY}

This is hospital based cross sectional study conducted at Birat Medical College and Teaching Hospital from May 2013 to April 2016. All cases attended with ectopic pregency during this period were included in the study. Written Informed consent was taken from patients. Eighty nine patients were treated for ectopic pregnancy by surgical method during the above mentioned period. Age of the patients, period of amenorrhoea, presence of previous surgery, site of ectopic pregnancy, any postoperative complications and total period of hospital stay were recorded. Data entry was done in Microsoft Excel, 2007 software and data analysis was done by SPSS software version 17 . Frequency table was obtained and mean was calculated.

\section{RESULTS}

Total 89 cases of ectopic pregnancies were analyzed in this cross sectional study. All were tubal pregnancies. Mean age of patient was 28.12 years, ranging from 18 years to 42 years. (Table 1)

Two of 89 cases did not know the last menstrual period, so period of amenorrhoea could not be calculated. Mean period of amenorrhoea while presenting to hospital was 6.57 weeks, ranging from 5 weeks to 11 weeks. (Table 2)

Out of 89 cases, 15 cases had history of previous surgeries in past. Among them, 12 cases (13.95\%) had undergone caesarean section in past, out of which, 2 cases had previous two caesarean section operations. Three cases had undergone laparotomy in past - two were for ectopic pregnancy and other one was for other gynecological problem, indications not clarified.

Ampulla of the fallopian tube was the most common site for the ectopic pregnancy $(n=64,71.91 \%)$, followed by isthmus $(n=14,15.73 \%)$, fimbrial $(n=8,8.99 \%)$ and cornual $(n=3$, 3.37\%) (Table 3)

Mean period of total hospital stay was 2.9 days, ranging from 2 day to 4 days. (Table 4 ).

Five cases $(5.61 \%)$ developed febrile illness on second postoperative day (fever up to $101^{\circ} \mathrm{F}$ ) which subsided subsequently. There was no maternal mortality. All cases were managed by laparoscopic surgery with no conversion to laparotomy.

Table 1. Age distribution of patients $(n=89)$

\begin{tabular}{|lll|}
\hline Age & Number & Percent \\
\hline$<20$ years & 2 & 2.25 \\
\hline $20-29$ years & 53 & 59.55 \\
\hline $30-39$ years & 3 & 235.95 \\
\hline$>40$ years & 2 & 2.25 \\
\hline
\end{tabular}

Table 2. Distribution of patients according to Weeks of Amenorrhoea $(n=89)$

\begin{tabular}{|lll|}
\hline Weeks of amenorrhea & Number & Percent \\
\hline$<6$ weeks & 16 & 17.98 \\
\hline $6-8$ weeks & 48 & 53.93 \\
\hline $8-10$ weeks & 20 & 22.48 \\
\hline$>10$ weeks & 3 & 3.37 \\
\hline Don't know & 2 & 2.24 \\
\hline
\end{tabular}


Table 3. Distribution of Site of ectopic pregnancy $(n=89)$

\begin{tabular}{lcc} 
Site & Number & Percent \\
\hline Fimbrial & 8 & 8.99 \\
\hline Ampullary & 64 & 71.91 \\
\hline Isthmic & 14 & 15.73 \\
\hline Cornual & 3 & 3.37 \\
\hline
\end{tabular}

Table 4. Distribution of patients according Period of hospital stay $(n=89)$

\begin{tabular}{|ccc|}
$\begin{array}{l}\text { Period of hospital } \\
\text { stay(Days) }\end{array}$ & Number & Percent \\
\hline 1 & 2 & 2.24 \\
\hline 2 & 12 & 13.49 \\
\hline 3 & 56 & 62.92 \\
\hline 4 & 15 & 16.85 \\
\hline 5 & 4 & 4.50 \\
\hline
\end{tabular}

\section{DISCUSSION}

Ectopic pregnancy is an emergency condition in obstetrics with increased chances of maternal mortality, morbidity and compromise in future pregnancy. ${ }^{1}$ Therefore, early diagnosis and prompt treatment are important factors in managing the ectopic pregnancies. Ectopic pregnancy can be diagnosed early with urine pregnancy test and transvaginal sonography.

Tubal pregnancy occurs in $97 \%$ of all ectopic pregnancies. Out of tubal pregnancies, $70 \%$ occur in ampulla, $12 \%$ in isthmus, and $11 \%$ in fimbrial and $3 \%$ in cornua. ${ }^{5}$ In our study, all 89 cases of ectopic pregnancies were tubal pregnancies. Of total ectopic pregnancies, $71.91 \%$ (64) were in ampulla, $15.73 \%(14)$ in isthmus, $8.98 \%(8)$ in fimbrial end and $3.34 \%(3)$ in cornua (Table 3 ). In a study by Chaudhary P et al, out of 43 ectopic pregnancies, $76 \%$ was ampullary, $16.27 \%$ was isthmic, $4.65 \%$ was cornual and $2.33 \%$ was infundibular. ${ }^{1}$

In present study, Mean age of patients was 28.12 years, ranging from 18 years to 42 years (Table 1 ) and the mean gestational age at presentation was 6.57 weeks (Table 2). Pradhan $\mathrm{P}$ et all conducted a retrospective study with 36 patients of ectopic pregnancies and the mean age was 30.1 years and mean gestational age was 6.9 weeks. ${ }^{6}$ Mean age of patients with ectopic pregnancy was 28.3 years and mean gestational age was 6.0 weeks. $^{7}$ Which keeps similarily with present study.
In our study, out of 89 cases, 12 cases (13.95\%) had undergone caesarean section in past, out of which 2 cases had previous two caesarean section operation. Three cases had undergone laparotomy in past, two (2.24\%) were for ectopic pregnancy and other one was for other gynecological problem. Shah et al analyzed 38 patients of ectopic pregnancy, $7.8 \%$ had previous ectopic pregnancy and $10 \%$ had prior caesarean section. Risk factors may not be present in all cases. ${ }^{8}$ Likewise, out of 49 patients, $26.55 \%$ had history of previous surgery and $16.3 \%$ had previous ectopic pregnancy.

Treatment of ectopic pregnancy by laparoscopy is preferred surgical method over traditional laparotomy as it offers advantages of early recovery, less postoperative pain and shorter hospital stay. Chaudhary $P$ et al retrospectively studied 43 cases of ruptured and unruptured ectopic pregnancies and all were managed by laparoscopy. Laparotomy was not done to manage the ectopic pregnancies. ${ }^{1}$ Ding DC et al compared the surgical morbidity of laparoscopy and laparotomy performed to manage ectopic pregnancies and concluded that laparoscopy is more beneficial and safer than to that of laparotomy. In our study, all cases of ectopic pregnancy were managed successfully by laparoscopy. There was no conversion to laparotomy. There was no maternal mortality due to ectopic pregnancy.

Safety and feasibility of laparoscopic management of ectopic pregnancy is well documented in various studies. Of 32 patients of ectopic pregnancies, 37.5\% were managed by laparoscopy and $62.5 \%$ by laparotomy in a study in Nepal. ${ }^{9}$ Martin F et al analyzed 54 ectopic pregnancy, in which $46 \%$ was managed by laparoscopy, 28\% undergone laparoscopy with subsequent conversion to laparotomy and $26 \%$ had primary laparotomy. ${ }^{10}$ These earlier studies are contrary to our study, but more recent studies show that most of the cases are now successfully managed by laparoscopy. Rizzuto $M$ et al studied the trends of laparoscopy for management of ectopic pregnancy. In 2003, only $40 \%$ were managed by laparoscopy, in 2004 , it was $85 \%$ and by $2006,100 \%$ cases of ectopic pregnancies were managed by laparoscopy. ${ }^{11}$ similarly, among 98 cases treated by laparoscopy, the procedure was successful in 95 cases (97.1\%). Laparotomic conversion was required in 3 cases to conclude the operation. ${ }^{3}$ In a study by Liz $\mathrm{G}$ et al, 215 patients of ectopic pregnancy underwent operative laparoscopy and all were treated successfully with no perioperative complications. ${ }^{12}$ 
Sagiv et al analyzed 101 patients of ectopic pregnancy who were treated by laparoscopy, and all were managed successfully except one case required conversion to laparotomy. No intraoperative or postoperative complications occurred. ${ }^{13}$ Takeda A et al analyzed 112 cases of ectopic pregnancy who were treated by laparoscopy surgery, in all cases there was no need to laparotomic conversion. ${ }^{14}$ Out of 533 patients who underwent surgical management for ectopic pregnancy, 465 (86.5\%) underwent laparoscopic procedure and $10.9 \%$ (51/465) converted to laparotomy. ${ }^{15}$ Laparoscopy can be performed to manage the most of the ectopic pregnancies. When compared with laparotomy, laparoscopic procedure is associated with shorter hospital stay and less postoperative adhesion. ${ }^{16}$

Total hospital stay was 2.2 days in laparoscopic group and 5.4 days in laparotomic group in a study by Leendorff $P$ and concluded that patients treated by laparoscopy had shorter hospital stay and shorter convalescence than from laparotomic group( 11 days Vs 24 days). ${ }^{4}$ In present study, 56 patients(62.92\%) were discharged on third postoperative day with mean period of hospital stay of 2.9 days (Table 4$)$. In a study in London University Hospital over a period of 4 years, $69 \%$ of the patients who underwent operative laparoscopy for ectopic pregnancy were discharged within 24 hours. ${ }^{17}$

\section{LIMITATIONS OF STUDY}

Due to small sample size, the finding could not be generalized in a large population.

\section{CONCLUSION}

Management of ectopic pregnancy by laparoscopy seems to be effective with minimal surgical morbidity. Further study with large sample size is necessary to justify the safety and efficacy of laparoscopy in the management of ectopic pregnancy.

\section{ACKNOWLEDGEMENT}

We would like to acknowledge all patients who were enrolled in this study.

\section{CONFILCT OFINTEREST}

None.

10. Martyn F, Kerkhoff B. The management of ectopic pregnancy. $r$ Med J. 2008 Mar;101(3):75-7.

11. Rizzuto MI, Oliver R, Odejinmi F. Laparoscopic management of ectopic pregnancy in the presence of a significant haemoperitoneum. Arch Gynecol Obstet. 2008 May;277(5):433-6. Epub 2007 Sep 29.

12. LiZG, Leng JH, Lang JH, Liu ZF, Sun DW, Lan Z. Laparoscopic surgery in patients with hypovolemic shock due to ectopic pregnancy. Chin Med Sci J. 2005 Mar;20(1):40-3.

13. Sagiv R, Debby A, Sadan O, Malinger G, Glezerman M, Golan A. Laparoscopic surgery for extrauterine pregnancy in hemodynamically unstable patients. J Am Assoc Gynecol Laparosc. $2001 \mathrm{Nov} ; 8(4): 529-32$.

14. Takeda A, Manabe S, Mitsui T, Nakamura H. Management of patients with ectopic pregnancy with massive hemoperitoneum by laparoscopic surgery with intraoperative autologous blood transfusion. J Minim Invasive Gynecol. 2006 Jan-Feb;13(1):43-8.

15. Cooray $\mathrm{H}$, Harilall M, Farquhar CM. A six-year audit of the management of ectopic pregnancy. Aust N Z J Obstet Gynaecol.2002 Nov;42(5):538-42.

16. Agdi M, Tulandi T. Surgical treatment of ectopic pregnancy. Best Pract Res Clin Obstet Gynaecol. 2009 Aug;23(4):519-27. doi: 10.1016/j.bpobgyn.2008.12.009. Epub 2009 Feb 23.

17. Deepa J, Oladimeji O, Funlayo O. Factors that determine patient satisfaction after surgical treatment of ectopic pregnancy: improving the patient journey. Eur J Obstet Gynecol Reprod Biol. 2014 Jul;178:60-5. 